\title{
Subsensitivity to bronchoprotection against adenosine monophosphate challenge following regular once-daily formoterol
}

\author{
I. Aziz*, K.S. Tan*, I.P. Hall+, M.M. Devlin*, B.J. Lipworth*
}

Subsensitivity to bronchoprotection against adenosine monophosphate challenge following regular once-daily formoterol. I. Aziz, K.S. Tan, I.P. Hall, M.M. Devlin, B.J. Lipworth CERS Journals Ltd 1998.

ABSTRACT: Regular treatment with inhaled long-acting $\beta_{2}$-agonists leads to subsensitivity to their bronchoprotective effects, although the effect of dosing frequency on this subsensitivity is not known. The aim of this study was to assess whether a oncedaily dosing regimen with formoterol might be associated with a lesser degree of subsensitivity.

In a randomized placebo-controlled double-blind, double-dummy crossover study 10 asthmatics treated with inhaled steroids (mean age $31 \mathrm{yrs}$, forced expiratory volume in one second (FEV1) $82 \%$ predicted) received 1 week of treatment with: formoterol dry powder $24 \mu \mathrm{g}$ twice daily $(08: 00$ and $20: 00 \mathrm{~h}$ ); formoterol $24 \mu \mathrm{g}$ once daily (20:00 h); or identical placebo. Adenosine monophosphate (AMP) bronchial challenge was performed $12 \mathrm{~h}$ after the first and the last dose of each treatment.

There was significant loss of protection with formoterol twice daily between the first and last dose (geometric mean provocative concentration causing a $20 \%$ fall in FEV1 (PC20)): 475 versus $129 \mathrm{mg} \cdot \mathrm{mL}^{-1}$ (a 3.7 -fold loss, $\left.p=0.006\right)$ and with formoterol once daily: 367 versus $127 \mathrm{mg} \cdot \mathrm{mL}^{-1}$ (a 2.9-fold loss, $p=0.005$ ), compared with placebo: 71 versus $75 \mathrm{mg} \cdot \mathrm{mL}^{-1}$ (nonsignificant). There was no significant difference in the degree of loss of protection between formoterol once and twice daily. For first-dose protection there was a significant difference between active treatments and placebo, but after the last dose the residual protection between active treatments and placebo was not significant.

Thus, in patients taking inhaled corticosteroids, regular formoterol $24 \mu \mathrm{g}$ once daily induces a similar degree of subsensitivity to adenosine monophosphate bronchial challenge as with formoterol $24 \mu \mathrm{g}$ twice daily. This in turn suggests that even with a 24-h dosing interval there is the development of tolerance to formoterol by prolonged occupancy of airway $\beta_{2}$-adrenoceptors.

Eur Respir J 1998; 12: 580-584.

Regular twice-daily use of long-acting $\beta$-agonists has been shown to be associated with the development of subsensitivity to their bronchoprotective effects against different bronchoconstrictor stimuli, such as histamine, methacholine, exercise and allergens [1-7]. This phenomenon ap-pears to occur even in patients receiving concomitant inhaled steroid therapy. All of these studies showing subsensitivity have evaluated the effects of twice-daily longacting $\beta_{2}$-agonists which could be associated with continuous $24 \mathrm{~h}, \beta_{2}$-adrenoceptor occupancy. It is unknown whether once-daily administration of long-acting $\beta_{2}$-agonists might ob-viate the development of subsensitivity and allow partial recovery of $\beta_{2}$-adrenoceptor downregulation, as a consequence of a potential period of receptor-free occupancy. In this respect, in a study evaluating the diurnal profile of a single $12 \mu \mathrm{g}$ dose of formoterol (via a pressurized metered-dose inhaler (pMDI)), there was no significant residual ef-fect on airway tone (as the forced expiratory volume in one second (FEV1)) or methacholine challenge at $24 \mathrm{~h}$ after administration, compared with placebo [8].
*Dept of Clinical Pharmacology and Therapeutics, Ninewells Hospital and Medical School, University of Dundee, Dundee, UK +Dept of Medicine, Division of Therapeutics, University Hospital of Nottingham, Nottingham, UK.

Correspondence: B.J. Lipworth

Dept of Clinical Pharmacology and

Therapeutics

Ninewells Hospital and Medical School

University of Dundee

Dundee DD1 9SY

UK

Fax: 441382644972

Keywords: Adenosine monophosphate formoterol

once-daily

subsensitivity

Received and accepted without revision March 151998

Funded by a research grant from the University of Dundee. I.P. Hall is supported by the National Asthma Campaign.
The present study was designed to determine whether once-daily treatment with a long-acting $\beta$-agonist, formoterol, was associated with less receptor subsensitivity as compared with twice-daily therapy. To render the study clinically relevant adenosine monophosphate (AMP) was used as the bronchoconstrictor stimulus, because it is an indirectly acting agent which causes the release of inflammatory mediators from mast cells. This is likely to reflect other indirectly acting stimuli that occur in real life, such as allergen, cold air or exercise challenge. Clinically, one important aspect of the study was to perform the AMP challenge test $12 \mathrm{~h}$ after the drug was administered, because the airways would be at their most vulnerable to the bronchoconstrictor stimuli at the time before the next dose is due. An inclusion criterion for the study was to ensure that patients were already taking inhaled corticosteroids, in order to reflect the recommended British Thoracic Society guidelines for using long-acting $\beta_{2}$-agonists [9]. 


\section{Methods}

\section{Subjects}

Ten asthmatic subjects (five male and five female), aged $30.8 \pm 4.3$ yrs (mean \pm SEM), all taking inhaled corticosteroids at a dose of 400 (200-2000) $\mu \mathrm{g} \cdot \mathrm{day}^{-1}$ (median (range)), all using inhaled $\beta_{2}$-agonists on an as-required basis for symptomatic relief ( $<4$ puffs.day $\left.{ }^{-1}\right)$ were recruited to take part in the study. All had stable asthma according to the American Thoracic Society criteria [10] for at least 3 months before taking part in the study and no one had taken oral steroids during this time. Baseline spirometry showed FEV1 $2.95 \pm 0.23 \mathrm{~L}, 82 \pm 4.5 \%$ predicted and forced midexpiratory flow (FEF25-75\%) 2.51 $\pm 0.30 \mathrm{~L} \cdot \mathrm{s}^{-1}, 57.8 \pm$ $5.9 \%$ predicted (means \pm SEM). All of the randomized patients had an unknown genotype before entry into the study. Patients were subsequently typed for $\beta_{2}$-adrenoceptor polymorphisms in order to assess whether there was a preponderance of a particular polymorphism that may have biased the sample. All gave written informed consent before being randomized in the double-blind, double-dummy crossover study, which was approved by the Tayside committee on medical research ethics. A full physical examination, haematological and biochemical parameters were normal before inclusion in the study.

\section{Study design}

Subjects were randomized to receive one-week treatment with either inhaled formoterol $24 \mu \mathrm{g}$ twice daily, inhaled placebo twice daily or inhaled placebo (morning) and inhaled formoterol $24 \mu \mathrm{g}$ (evening). Formoterol was delivered by dry-powder capsules, $12 \mu \mathrm{g}$ per capsule (Foradil, Geigy Pharmaceuticals, Horsham, UK). The doses were chosen to be within the manufacturer's recommended total daily dose range of 24-48 $\mu \mathrm{g}$. Placebo was delivered using identically prepared capsules containing lactose. The medication was taken between 20:00 and 21:00 $\mathrm{h}$ for the evening dose and between 08:00 and 09:00 $\mathrm{h}$ for the morning dose. The first and last doses were taken in the evening before each respective visit. There was a one-week run-in period before randomization and a minimum of oneweek washout between each of the randomized treatments. From the start of the run-in period until the end of the study, all $\beta_{2}$-agonist therapy was stopped and substituted with inhaled ipratropium bromide (Atrovent Forte, Boehringer Ingelheim, Bracknell, UK) for symptomatic rescue relief.

Subjects attended the laboratory for the first visit between 08:00 and 09:00 $\mathrm{h}$ after taking the first dose on the previous evening and withholding the second dose, which was taken in the morning after the AMP challenge. The second visit was 1 week later, after 7 days of each treatment, again $12 \mathrm{~h}$ after the last evening dose, when the second AMP challenge was performed. This was followed by the washout period before the next treatment cycle.

\section{Adenosine monophosphate bronchial challenge test}

The AMP bronchial challenge test was done using a breath-actuated Morgan Nebulizer Controller (P.K. Morgan,
Gillingham, UK) and a System 22 Acorn nebulizer (Mediaid, Pagham, UK), operated with $4 \mathrm{~mL}$ solution. The aerosols were inhaled through the mouth (the nose was clipped) via a mouthpiece. The nebulizer controller was driven by air at a pressure of $1.38 \mathrm{kPa}$ and inspiration triggered the delivery of the solution for $1 \mathrm{~s}$ over five breaths. AMP solution was freshly prepared each day using pharmaceutical grade adenosine 5' monophosphate (Sigma ${ }^{\circledR}, \mathrm{St}$ Louis, MO, USA) which was diluted to a range 0.09-400 $\mathrm{mg} \cdot \mathrm{mL}^{-1}$.

The FEV 1 was measured using a Vitalograph Compact spirometer (Vitalograph, Buckinghamshire, UK) according to the American Thoracic Society criteria [11]. The dilutent $0.9 \%$ saline was then inhaled for five breaths, FEV1 was measured after $90 \mathrm{~s}$ and the baseline value was measured. Doubling concentrations of AMP from 0.09$400 \mathrm{mg} \cdot \mathrm{mL}^{-1}$ were inhaled for five breaths after every 3 min and FEV1 was repeated after $90 \mathrm{~s}$ for each dilution. The test was continued until the FEV 1 had dropped by $>20 \%$ from the baseline level or the maximum concentration of $400 \mathrm{mg} \cdot \mathrm{mL}^{-1}$ had been given. The provocative concentration causing a $20 \%$ fall in FEV 1 (PC20) was calculated using a computer-assisted curve-fitting package (Biolab Assistant 1.1, University of Dundee, UK). If the FEV1 did not show a $20 \%$ fall after the maximum concentration had been given, or if the curve fitting revealed an extrapolated value $>800 \mathrm{mg} \cdot \mathrm{mL}^{-1}$, a censored $\mathrm{PC} 20$ value of $800 \mathrm{mg} \cdot \mathrm{mL}^{-1}$ (double the maximum concentration) was assigned for that test for the purpose of statistical analysis [12].

\section{Identification of $\beta_{2}$-adrenoceptor polymorphisms}

$\beta_{2}$-Adrenoceptor polymorphisms were identified as described previously [13]. In brief, genomic deoxyribonucleic acid (DNA) was extracted from whole blood and a 234 base pair fragment generated by polymerase chain reaction (PCR), which spanned the regions of interest. The primers used were 5': CCCAGCCACTGCGCTTACCT and 3': CCGTCTGCAGACGCTCGAAC. The genotype was determined by allele-specific oligonucleotide (ASO) hybridization using probes homologous for the Arg16, Gly16, Gln27 or Glu27 forms of the receptor. A random selection of PCR fragments was also directly sequenced to confirm the specificity of genotype determination by ASO.

\section{Statistical analysis}

The study was powered at $80 \%$ to detect differences in AMP PC20 of 1.5 doubling doses (within-subject $\mathrm{SD}=1.3$ doubling doses). The data for $\mathrm{PC}_{20}$ were $\log$ transformed before analysis. The change in $\log \mathrm{PC}_{20}$ protection was calculated as the geometric mean (and SEM)-fold difference, comparisons between the three treatments and for comparison of the first versus the last dose. For all parameters, comparisons within and between treatments were made using the Statgraphics software package (STSC Soft-ware Publishing Group, Rockville, MD, USA). The comparisons were made by multifactorial analysis of variance (MANOVA) using subjects, treatments and visits as factors for analysis, followed by Bonferroni multiple range testing. A probability value of $\mathrm{p}<0.05$ (two-tailed) was con- 
Table 1. - Spirometry, genotype and demographic data at recruitment

\begin{tabular}{|c|c|c|c|c|c|c|c|c|}
\hline$\overline{\text { Subject }}$ & $\begin{array}{l}\text { Age } \\
\text { yrs }\end{array}$ & Sex & $\begin{array}{l}\text { Genotype } \\
\text { locus } 16\end{array}$ & $\begin{array}{l}\text { Genotype } \\
\text { locus } 27\end{array}$ & $\begin{array}{c}\text { FEV1 } \\
\text { L }\end{array}$ & $\begin{array}{l}\text { FEV1 } \\
\% \text { pred }\end{array}$ & $\begin{array}{c}\text { FEF25-75\% } \\
\text { L } \cdot \mathrm{s}^{-1}\end{array}$ & $\begin{array}{c}\text { FEF25-75\% } \\
\% \text { pred }\end{array}$ \\
\hline 1 & 34 & $\mathrm{~F}$ & Gly-Gly & Glu-Glu & 2.38 & 82 & 2.33 & 62 \\
\hline 2 & 29 & $\mathrm{M}$ & Gly-Gly & Gln-Gln & 2.84 & 74 & 2.31 & 49 \\
\hline 3 & 21 & $\mathrm{~F}$ & Gly-Arg & Glu-Gln & 2.59 & 93 & 3.15 & 79 \\
\hline 4 & 60 & $\mathrm{M}$ & Gly-Arg & Glu-Gln & 2.02 & 63 & 1.29 & 37 \\
\hline 5 & 49 & $\mathrm{M}$ & Gly-Arg & Glu-Gln & 2.65 & 63 & 1.14 & 27 \\
\hline 6 & 20 & M & Gly-Gly & Glu-Glu & 3.85 & 79 & 2.59 & 49 \\
\hline 7 & 28 & $\mathrm{~F}$ & Gly-Arg & Glu-Gln & 3.50 & 105 & 2.58 & 63 \\
\hline 8 & 25 & $\mathrm{~F}$ & Gly-Gly & Glu-Glu & 2.85 & 95 & 3.09 & 75 \\
\hline 9 & 20 & $\mathrm{M}$ & Gly-Arg & Gln-Gln & 4.35 & 92 & 4.5 & 86 \\
\hline 10 & 22 & $\mathrm{~F}$ & Arg-Arg & Gln-Gln & 2.47 & 74 & 2.1 & 51 \\
\hline Mean & 30.8 & & & & 2.95 & 82 & 2.51 & 57.8 \\
\hline SEM & 4.3 & & & & 0.23 & 4.5 & 0.30 & 5.9 \\
\hline
\end{tabular}

F: female; M: male; FEV1: forced expiratory volume in one second; FEF25-75: forced mid-expiratory flow; Gly: glycine; Glu: glutamic acid; Arg: arginine; Gln: glutamine.

sidered as being significant and $95 \%$ confidence intervals ( $95 \% \mathrm{CI})$ for mean differences were also calculated. The genotype data were not subjected to statistical analysis because of the small number of subjects within a given genotype for each locus.

\section{Results}

Spirometry, genotype and demographic data on the patients at recruitment are shown in table 1. All subjects completed the study and no adverse effects were reported.

\section{Prechallenge FEVI}

The FEV1 $12 \mathrm{~h}$ after the first dose, prior to the AMP challenge during the active limbs of the trial, showed a small improvement compared with placebo (placebo: 2.85 $\mathrm{L}$; formoterol $24 \mu \mathrm{g}$ b.i.d.: $3.22 \mathrm{~L}$; formoterol $24 \mu \mathrm{g}$ o.d.: $3.12 \mathrm{~L}$ ), although this was not statistically significant (placebo versus formoterol $24 \mu \mathrm{g}$ b.i.d.: $\mathrm{p}=0.06$ ). This effect

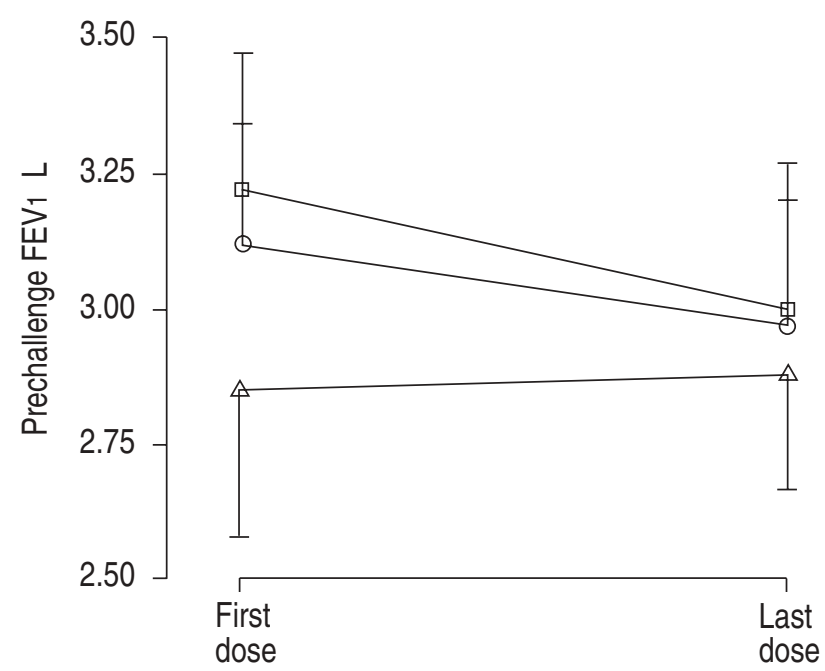

Fig. 1. - Forced expiratory volume in one second (FEV1) before adenosine monophosphate challenge measured at $12 \mathrm{~h}$ after the first and last doses for each of the three treatments (ý: placebo; ○: formoterol 24 $\mu \mathrm{g}$ o.d.; $\square$ : formoterol $24 \mu \mathrm{g}$ b.i.d.). Results are expressed as mean and SEM. was diminished after the last dose of regular treatment (placebo: $2.88 \mathrm{~L}$; formoterol $24 \mu \mathrm{g}$ b.i.d.: $3.00 \mathrm{~L}$; formoterol $24 \mu \mathrm{g}$ o.d.: $2.97 \mathrm{~L}$ ) (fig. 1).

\section{AMP bronchial challenge}

After the first dose there was significant difference in protection against AMP challenge between both active treatments and placebo: for formoterol $24 \mu \mathrm{g}$ b.i.d., a 6.7-fold difference $(95 \%$ CI 2.5-18.0), $\mathrm{p}=0.002$, and for formoterol $24 \mu \mathrm{g}$ o.d., a 5.2-fold difference (95\% CI 2.0-13.1), $\mathrm{p}=0.003$, compared with placebo. There was no difference between the two active treatments, after the first dose. After the last dose there were no significant differences between active treatments and placebo: for formoterol $24 \mu \mathrm{g}$ b.i.d., a 1.7-fold difference (95\% CI 0.9-3.3) and for formoterol $24 \mu \mathrm{g}$ o.d., a 1.7 -fold difference (95\% CI 0.6-5.0).

Within each treatment regimen there was a significant loss of protection between the first and last dose protec-

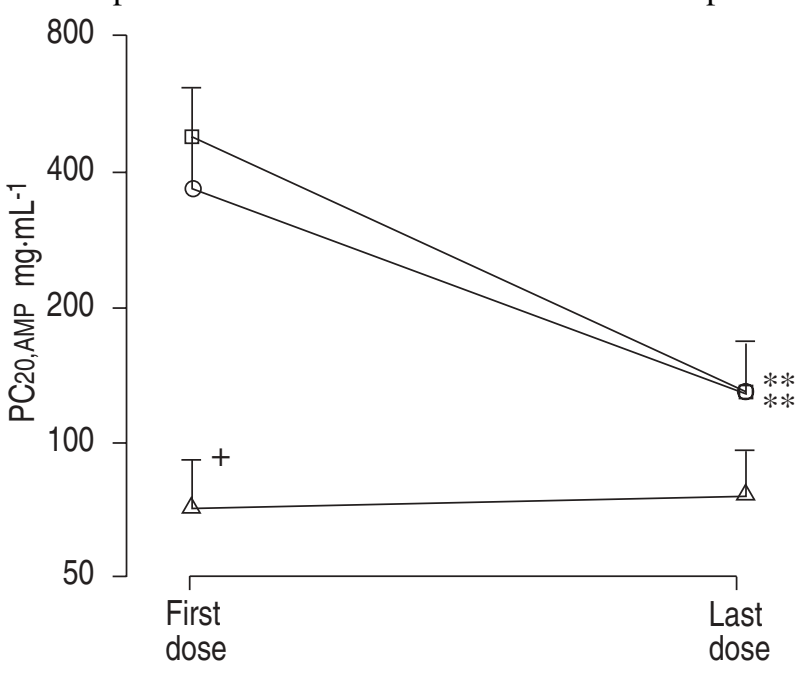

Fig. 2. - Provocative concentration of adenosine monophosphate (AMP) causing a $20 \%$ fall in the forced expiratory volume in one second (PC20,AMP) for each of the three treatments (ý: placebo; O: formoterol $24 \mu \mathrm{g}$ o.d.; $\square$ : formoterol $24 \mu \mathrm{g}$ b.i.d.), measured at $12 \mathrm{~h}$ after the first and last doses. Results are shown as mean and SEM. **: $\mathrm{p}<0.01$, significant difference between the first and last dose for formoterol $24 \mu \mathrm{g}$ o.d. and b.i.d.; $+: \mathrm{p}<0.005$ between active treatments and placebo at first dose. PC20,AMP is plotted on a $\log _{2}$ scale in order to show doubling doses. 
a)

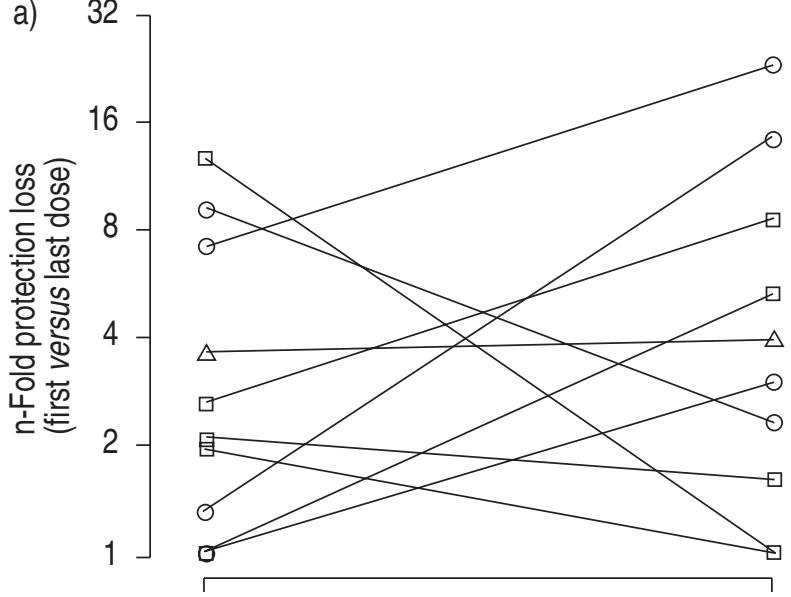

b) 32

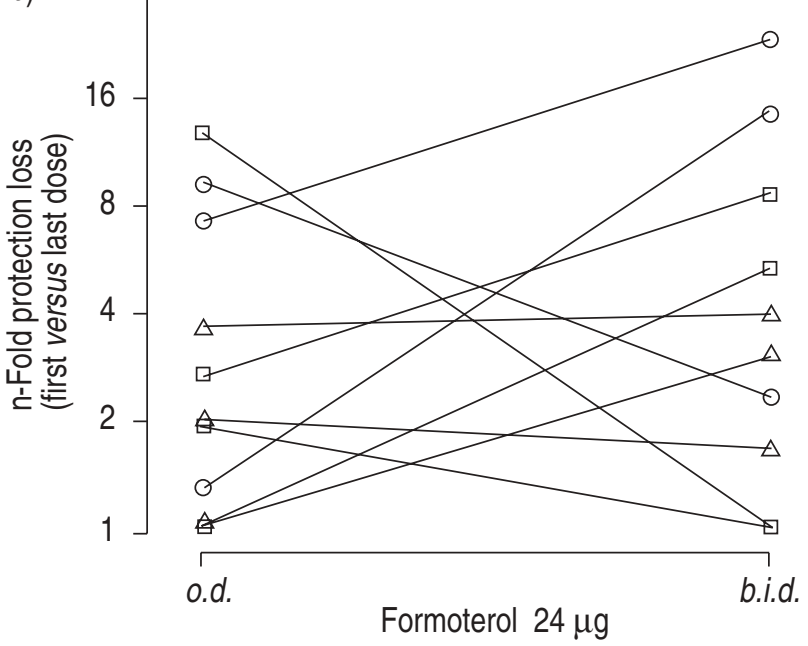

Fig. 3. - Individual data plotted to show the loss of protection in provocative concentration of adenosine monophosphate (AMP) causing $20 \%$ fall in the forced expiratory volume in one second ( $\mathrm{PC} 20, \mathrm{AMP})$ between first and last dose for once-daily and twice-daily treatment with formoterol. n-Fold loss of protection is plotted on a $\log _{2}$ scale in order to show doubling doses. The results are depicted to show the individual's genotype for loci 16 and 27 of the $\beta_{2}$-adrenoceptor. Data points for each individual with formoterol $24 \mu \mathrm{g}$ o.d. and b.i.d. are joined by a solid line. a) O: Gly16/Gly16 (n=4); 口: Gly16/Arg16 (n=5); ý: $\operatorname{Arg} 16 /$ $\operatorname{Arg} 16(\mathrm{n}=1) ; \mathrm{b})$ O: Glu27/Glu27 (n=3); 口: Glu27/Gln27 (n=4); ý: $\mathrm{Gln} 27 / \mathrm{G} \ln 27(\mathrm{n}=3)$.

tion: for formoterol $24 \mu \mathrm{g}$ b.i.d. (geometric mean) $\mathrm{PC} 20$ FEV1 for first versus last dose, 475 versus $129 \mathrm{mg} \cdot \mathrm{mL}^{-1}$, $\mathrm{p}=0.006$, a 3.7-fold difference (95\% CI 1.6-8.3), and for formoterol $24 \mu \mathrm{g}$ o.d., 367 versus $127 \mathrm{mg} \cdot \mathrm{mL}^{-1}, \mathrm{p}=0.005$, a 2.9-fold difference (95\% CI 1.5-5.6). There was no significant difference between the first and last doses for placebo: 71 versus $75 \mathrm{mg} \cdot \mathrm{mL}^{-1}$ (fig. 2 ).

Individual responses for the loss of protection between first and last dose are depicted in figure 3 according to genotype for $\beta_{2}$-adrenoceptor at loci 16 and 27 . All three subjects who were homozygous for Glu27 were also homozygous for Gly16. The data showed considerable interindividual variation in the degree of protection loss for both once- and twice-daily formoterol. There appeared to be no particular relationship between genotype and degree of subsensitivity with either once or twice-daily dosing.

\section{Discussion}

The results showed that regular, once-daily treatment with formoterol leads to the development of subsensitivity to its bronchoprotective effect, which is comparable to the subsensitivity produced by twice-daily therapy. This occurred despite the use of concomitant inhaled corticosteroid therapy. The finding of tachyphylaxis with a once-daily dosing regimen suggests that there must presumably have been a persistent degree of occupancy of airway $\beta_{2}$-adrenoceptors throughout the $24 \mathrm{~h}$ dosing interval. It has previously been shown that there is no detectable bronchodilatory activity at $24 \mathrm{~h}$ after stopping regular treatment with formoterol dry powder $24 \mu \mathrm{g}$ b.i.d. [14]. This, in turn, suggests that measuring the effects on basal bronchomotor tone cannot be used as a sensitive surrogate for detecting the persistent occupancy of airway $\beta_{2}$-adrenoceptors.

The doses of formoterol used were chosen to be within the manufacturer's recommended dose range of $24-48 \mu \mathrm{g}$. day $^{-1}$. Although there have been no previous studies looking specifically at protection loss with once-daily longacting $\beta_{2}$-agonist therapy, the studies by YATES et al. [2] with formoterol and GROVE and LIPWORTH [1] with salmeterol had similarities in their design to the present study in their evaluation of the bronchoprotective effect $12 \mathrm{~h}$ after dosing. In the study by YATES et al. [2] with methacholine challenge on steroid-naive patients, there was a 2.7-fold loss of protection between first and last dose of $24 \mu \mathrm{g}$ b.i.d. of formoterol dry powder given for 2 weeks. Values for the first and last dose protection compared with placebo were 4.4-fold and 1.5-fold, respectively. Grove and LipwORTH [1] reported only on the last-dose protection against histamine in steroid-treated asthmatics, after $50 \mu \mathrm{g}$ b.i.d. of salmeterol dry powder for 4 weeks, which showed a 1.5-fold residual protection compared with placebo. These data are similar to the results of the present study with AMP in terms of the degree of residual protection after the last dose, which was a 1.7-fold difference with both once- and twice-daily regimens. Taken together, these results sug-gest that the residual degree of protection is similar with either direct (methacholine and histamine) or indirect (AMP) challenge at $12 \mathrm{~h}$ after dosing, with both salmeterol and formoterol given on a regular basis.

In a study by EGBAGBE et al. [15] there was close agreement between the level of protection by terbutaline against AMP and histamine challenge, although only a single 500 $\mu \mathrm{g}$ dose of terbutaline was evaluated. O'ConNor et al. [16] showed that treatment with regular inhaled terbutaline produced a greater degree of subsensitivity for AMP than methacholine challenge. In their study there was a 4.2-fold loss of protection against AMP challenge after regular terbutaline, compared to a 3.7-fold loss with twice-daily formoterol in the present study.

In the studies by Cheung et al. [3] and Воотн et al. [4], there was no loss of the bronchodilatory effect after regular treatment with salmeterol $50 \mu \mathrm{g}$ b.i.d. In the present study there was a trend towards a diminished prechallenge FEV1 value between the first and last dose, which is similar to findings reported by YATES et al. [2] with formoterol $24 \mu \mathrm{g}$ b.i.d. for 2 weeks. This could be due to a decrease in the duration of the therapeutic bronchodilatory effect of formoterol with regular treatment, as the FEV1 was meas- 
ured after $1 \mathrm{~h}$ in the studies by Cheung et al. [3] and Воотн et al. [4], whilst in the study of YATES et al. [2] and the present study the FEV1 was measured $12 \mathrm{~h}$ after dosing. It is also important to mention that in the studies of CHEUNG et al. [3] and Воотн et al. [4] there was a $36 \mathrm{~h}$ washout after chronic dosing, which might conceivably have restored $\beta_{2}$-adrenoceptor function and hence the broncho-dilatory response. It should be pointed out that the present study was powered to detect bronchoprotective subsensitivity rather than bronchodilatory subsensitivity and hence it is not possible to draw any firm conclusions on pre-challenge FEV1 values with the present sample size. Furthermore, a proper $\beta_{2}$ agonist dose-response curve is necessary in order to detect bronchodilatory subsensitivity $[1,14]$. Studies with greater power are therefore required to in-vestigate whether bronchodilatory subsensitivity develops in the presence of regular, once-daily formoterol treatment.

A retrospective genotype analysis was performed in order to evaluate whether there was a preponderance of a particular polymorphism which may have biased the sample. From inspection of the individual data it was clear that the subsensitivity that developed with once- or twice-daily dosing regimens was independent of genotype at loci 16 and 27. In other words, the finding of subsensitivity with once-daily formoterol cannot be explained by a particular preponderance of a polymorphism in our sample, such as homozygous Gly16 [17]. Bronchoprotective subsensitivity occurs more readily than bronchodilatory subsensitivity, which may explain why there was no apparent relationship between the homozygous Gly16 genotype and the degree of loss of protection, even in association with formoterol $24 \mu \mathrm{g}$ twice daily. Larger prospective studies are underway to investigate further whether there is any association between $\beta_{2}$-adrenoceptor polymorphism and bronchoprotective subsensitivity.

In conclusion, regular treatment with inhaled formoterol induces subsensitivity to its bronchoprotective effect against adenosine monophosphate challenge, which is influenced neither by the dosing frequency nor by concomitant use of inhaled corticosteroids. This research disproves the hypothesis that the use of a $24 \mathrm{~h}$ dosing interval may obviate the development of subsensitivity. This suggests that, even with a once-daily dosing regimen, there is inadequate recovery of $\beta_{2}$-adrenoceptor downregulation, owing to prolonged receptor occupancy over a $24 \mathrm{~h}$ period. It would, therefore, seem rational to suggest that long-acting $\beta_{2}$-agonists could be used in the same way as short-acting $\beta_{2}$-agonists, on an as-required basis on top of optimized inhaled steroid therapy, up to a maximum recommended daily dosage. In this respect, formoterol has an advantage over salmeterol in that it has a fast onset of action and could, therefore, afford rapid relief of bronchospasm. For those patients with severe asthma who require regular formoterol, physicians should be aware that bronchoprotective subsensitivity occurs even with once-daily administration, and hence higher doses of rescue $\beta_{2}$-agonists might be required to obviate the effects of an acute bronchoconstrictor challenge.

\section{References}

1. Grove A, Lipworth BJ. Bronchodilator subsensitivity to salbutamol after twice daily salmeterol in asthmatic patients. Lancet 1995; 346: 201-206.

2. Yates DH, Sussman HS, Shaw MJ, Barnes PJ, Chung KF. Regular formoterol treatment in mild asthma: effect on bronchial responsiveness during and after treatment. Am J Respir Crit Care Med 1995; 152: 1170-1174.

3. Cheung D, Timmers MC, Zwinderman AH, Bel EH, Dijkman JH, Sterk PJ. Long term effects of long-acting beta-2 adrenoceptor agonist salmeterol on airway hyperresponsiveness in patients with mild asthma. $N$ Engl $J$ Med 1992; 327: 1198-1203.

4. Booth H, Bish R, Walters J, Whitehead F, Walters EH. Salmeterol tachyphylaxis in steroid treated asthmatic subjects. Thorax 1996; 51: 1100-1104.

5. Ramage L, Lipworth BJ, Ingram CG, Cree IA, Dhillon DP. Reduced protection against exercise induced bronchoconstriction after chronic dosing with salmeterol. Respir Med 1994; 88: 363-368.

6. Giannini D, Carletti A, Dente FL, et al. Tolerance to the protective effect of salmeterol on allergen challenge. Chest 1996; 110: 1452-1457.

7. Kalra S, Swystun VA, Bhagat R, Cockcroft DW. Inhaled corticosteroids do not prevent the development of tolerance to the bronchoprotective effect of salmeterol. Chest 1996; 109: 953-956.

8. Rabe KF, Jorres R, Novak D, Behr N, Magnussen H. Comparison of the effects of salmeterol and formoterol on airway tone and responsiveness over 24 hours in bronchial asthma. Am Rev Respir Dis 1993; 147: 1436-1441.

9. British Thoracic Society. Guidelines on the management of asthma. Thorax 1997; 52: S1-S21.

10. American Thoracic Society. Standards for the diagnosis and care of patients with chronic obstructive pulmonary disease (COPD) and asthma. Am Rev Respir Dis 1987; 136: 225-244.

11. American Thoracic Society. Standardisation of spirometery - update. Am Rev Respir Dis 1987; 136: 1285-1298.

12. Chinn S. Repeatability and method comparison. Thorax 1991; 46: 454-456.

13. Hall IP, Wheatley A, Wilding P, Liggett SB. Association of Glu $27 \beta_{2}$-adrenoceptor polymorphism with lower airways reactivity in asthmatic subjects. Lancet 1995; 345 : 1213-1214.

14. Newnham DM, Grove A, McDevitt DG, Lipworth BJ. Subsensitivity of bronchodilator and systemic beta- 2 adrenoceptor responses after regular twice daily treatment with formoterol dry powder in asthmatic patients. Thorax 1995; 50: 497-504.

15. Egbagbe E, Pavord ID, Wilding P, Thompson-Coon J, Tattersfield AE. Adenosine monophosphate and histamine induced bronchoconstriction: repeatability and protection by terbutaline. Thorax 1997; 52: 239-243.

16. O'Connor BJ, Aikman SL, Barnes PJ. Tolerance to the nonbronchodilator effects of inhaled $\beta_{2}$-agonists in asthma. N Engl J Med 1992; 327: 1204-1208.

17. Hall IP. $\beta_{2}$-adrenoceptor polymorphisms: are they clinically important. Thorax 1996; 51: 351-353. 